\begin{tabular}{|c|c|c|}
\hline BIC & $\begin{array}{c}\text { BIODIK: Jurnal IImiah Pendidikan Biologi } \\
\text { ISSN 2580-0922 (online), ISSN 2460-2612 (print) } \\
\text { Volume 07, Nomor 04, Tahun 2021, Hal. 177-182 } \\
\quad \text { Available online at: } \\
\text { https://online-journal.unja.ac.id/biodik }\end{array}$ & \begin{tabular}{l|l} 
BIODIK & $(1)$
\end{tabular} \\
\hline
\end{tabular}

Research Article

open 2 Access

\title{
Analisis Sikap Ilmiah Mahasiswa Pada Praktikum Mata Kuliah Biologi Umum Di UIN Sulthan Thaha Saifuddin Jambi
}

\section{(Analysis of Student Scientific Attitudes in Practicum of General Biology Course at UIN Sulthan Thaha Saifuddin Jambi)}

\author{
Devi Novallyan ${ }^{\star 1}$, Reny Safita 2 , Dwi Gusfarenie ${ }^{3}$ Sumitro ${ }^{4}$ \\ 1,2,3 Staf Pengajar Tadris Biologi FITK UIN Sulthan Thaha Syaifuddin Jambi \\ Jl. Jambi Ma. Bulian KM. 16, Simp. Sei. Duren, Jaluko, Kec. Jaluko, Muaro Jambi, Jambi 36657 \\ ${ }^{4}$ Staf Pengajar Tadris Biologi FTIK IAIN Kerinci \\ JI. Pelita IV, Sumur Gedang, Pesisir Bukit, Kabupaten Kerinci, Jambi 3711 \\ ${ }^{*}$ Corresponding Authors: devienovallyan@uinjambi.ac.id
}

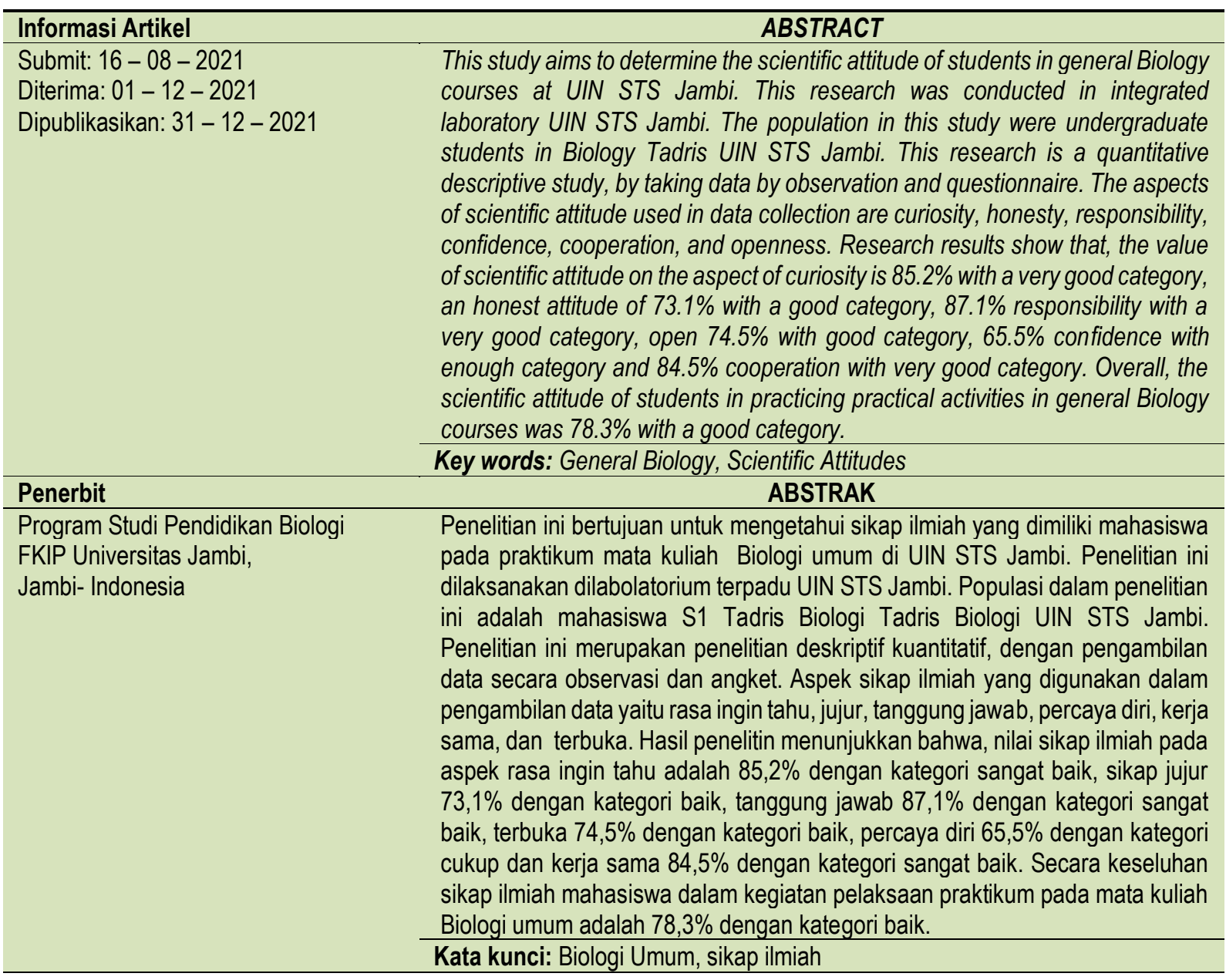




\section{(i) (2)}

BY NC SA

This BIODIK : Jurnal IImiah Pendidikan Biologi is licensed under a CC BY-NC-SA (Creative Commons Attribution-ShareAlike 4.0 International License)

\section{PENDAHULUAN}

Sumber daya manusia yang berkualitas sangat diperlukan dalam pembangunan bangsa khususnya dalam bidang pendidikan. Tujuan utama pendidikan adalah membantu mahasiswa untuk dapat menemukan makna baru mengenai apa yang dipelajari (Martin, 1997). Dengan demikian diperlukan pembelajaran yang mampu menciptakan suasana atau kegiatan yang kondusif sehingga pembelajaran menjadi bermakna bagi mahasiswa. Menurut Ausubel dalam Pujiastuti (2013) untuk dapat mewujudkan pembelajaran bermakna maka setiap individu yang belajar harus dapat mengaitkan pengetahuan baru ke konsep atau proposisi (hubungan antar konsep) yang relevan yang sudah diketahui. Biologi merupakan salah satu ilmu yang erat hubungan dengan alam. Biologi berisi fakta, konsep, dan proposisi (hubungan antar konsep) yang relevan.

Pembelajaran biologi bertujuan untuk mengembangkan kompetensi mahasiswa, agar mahasiswa mampu memahami alam sekitar melalui proses mencari tahu dan berbuat berdasarkan pengalaman langsung. Hal ini akan membantu mahasiswa untuk memperoleh pemahaman yang lebih mendalam. Melalui pembelajaran Biologi sikap ilmiah diharapkan mahasiswa dapat lebih dikembangkan yaitu berupa sikap dan nilai yang meliputi rasa ingin tahu, jujur, terbuka, kritis, tekun, tanggung jawab disiplin, peduli terhadap lingkungan dan bekerjasama. Salah satu kegiatan dalam pemeblajaran Biologi yang dapat meningkatkan sikap ilmiah yaitu praktikum..

Praktikum menjadi strategi pembelajaran yang baik bagi mahasiswa untuk mengembangkan keterampilan manipulatif, keterampilan hands on dan mind on, karena mahasiswa ditantang untuk aktif dalam memecahkan masalah, berpikir kritis dan kreatif dalam mengungkap fakta, membangun konsep, dan menerapkan prinsip-prinsip agar menjadi lebih bermakna. Penguatan fungsi praktikum sebagai kegiatan laboratorium pada pembelajaran berperan dalam memperkuat konsep-konsep yang disajikan dalam perkuliahan di antaranya dikemukakan oleh Dwiyanti (1999) yang menyebutkan fungsi praktikum adalah: membina sikap ilmiah. Penanaman sikap ilmiah melalui metode pembelajaran yang tepat akan sangat berpengaruh pada pembinaan sikap positif terhadap konsep atau topik yang sedang dipelajari. Oleh karena itu, sikap ilmiah perlu dibina sedini mungkin bagi mahasiswa, sehingga mereka dapat menjadi pribadi yang baik dan menjadi generasi penerus yang berkualitas (Sukaesih, 2011).

Menurut Sudijono (2008), sikap merupakan bagian dari tingkah laku manusia sebagai gejala atau gambaran kepribadian yang memancar keluar. Dengan demikian sikap merupakan tingkah laku atau perbuatan akibat reaksi seseorang terhadap orang lain atau benda tertentu.Aspek sikap ilmiah yaitu : Sikap ingin tahu, sikap ingin mendapatkan sesuatu yang baru, sikap kerjasama, sikap tidak putus asa, sikap tidak berprasangka, sikap jujur, sikap bertanggung jawab, sikap berfikir bebas, dan sikap kedisiplinan diri (Harlen dalm Fakhrudin, 2010).

Sikap ilmiah diartikan sebagai suatu kecenderungan, kesiapan, kesediaan, seseorang untuk memberikan respon/tanggapan/tingkah laku secara ilmu pengetahuan dan memenuhi syarat (hukum) ilmu pengetahuan yang telah diakui kebenarannya. Setiap individu yang memiliki sikap ilmiah, memiliki kualitas seperti realistis memiliki perhatian terhadap lingkungan sekitar, menghindari generalisasi yang didasarkan pada fenomena dan tidak mempercayai keyakinan dogmatis (Anagun and yasar, 2009). 
Menurut Kartono (2012), sikap ilmiah memiliki peran yang penting dalam menemukan konsep suatu pembelajaran serta mahasiswa dapat membangun gagasan baru sewaktu mereka berinteraksi dengan suatu gejala. Sikap ilmiah merupakan kecenderungan orang atau individu untuk bertindak atau berperilaku dalam memecahkan suatu masalah secara sistematis melalui langkah-langkah ilmiah (Sukeesih, 2011).

\section{METODE PENELITIAN}

Jenis penelitian ini adalah penelitian deskriptif kuantitatif, dimana penelitian ini dapat memberikan gambaran objektif dengan data yang ada mengenai sikap ilmiah mahasiswa terhadap praktikum mata kuliah Biologi umum. Penelitian ini dilaksanakan pada semester ganjil 2019/2020 pada Jurusan Tadris Biologi UIN STS Jambi pada mahasiswa semester satu berjumlah 64 orang.

Sikap IImiah mahasiswa yang terdiri dari 6 indikator yaitu: (1) rasa ingin tahu, (2) jujur, (3) tanggung jawab, (4) terbuka, (5) percaya diri dan (6) kerja sama. Pengumpulan data sikap ilmiah mahasiswa dengan menggunakan lembar observasi. dan dilakukan pada saat praktikum. Analisis data dilakukan dengan teknik analisa deskriptif kuantitatif, yang bertujuan untuk mendeskripsikan data sikap ilmiah. Interval dan kategori sikap ilmiah mahasiswa yang digunakan tertera pada Tabel 1.

Tabel 1. Pengkategorian nilai sikap ilmiah mahasiswa

\begin{tabular}{|c|c|c|}
\hline No. & Interval nilai (\%) & Kategori \\
\hline 1 & $80-100$ & Sangat baik \\
\hline 2 & $66-79,9$ & Baik \\
\hline 3 & $56-65,9$ & Cukup \\
\hline 4 & $40-45,9$ & Kurang \\
\hline 5 & $<40$ & Kurang sekali \\
\hline
\end{tabular}

\section{HASIL PENELITIAN DAN PEMBAHASAN}

Hasil observasi sikap ilmiah mahasiswa pada praktikum mata kuliah Biologi umum dapat dilihat pada Tabel 2.

Tabel 2. Sikap ilmiah mahasiswa pada praktikum Biologi umum

\begin{tabular}{|c|c|c|c|c|c|c|c|}
\hline \multirow[t]{2}{*}{ No. } & \multirow[t]{2}{*}{ Indikator sikap ilmiah } & \multicolumn{4}{|c|}{ Sikap ilmiah praktikum ke- } & \multirow{2}{*}{$\begin{array}{l}\text { Rata-rata } \\
\text { sikap ilmiah } \\
(\%)\end{array}$} & \multirow[t]{2}{*}{ Kategor } \\
\hline & & $\begin{array}{c}1 \\
(\%)\end{array}$ & $\begin{array}{c}11 \\
(\%)\end{array}$ & III (\%) & IV (\%) & & \\
\hline 1 & Rasa ingin tahu & 83,4 & 85,6 & 84,3 & 87,3 & 85,2 & Sangat baik \\
\hline 2 & Jujur & 74,6 & 72,3 & 72,4 & 73,2 & 73,1 & Baik \\
\hline 3 & Tanggung jawab & 85,6 & 89,2 & 87,4 & 86,2 & 87,1 & Sangat baik \\
\hline 4 & Terbuka & 74,2 & 74,7 & 76,7 & 72,4 & 74,5 & Baik \\
\hline 5 & Percaya diri & 65,3 & 67,2 & 64,3 & 65,3 & 65,5 & Cukup \\
\hline 6 & Kerja sama & 83,6 & 84,4 & 83,6 & 86,2 & 84,5 & Sangat baik \\
\hline \multicolumn{6}{|c|}{ Rata-rata keseluruhan } & 78,3 & Baik \\
\hline
\end{tabular}

Berdasarkan Tabel 2 di atas dapat diketahui nilai rata-rata persentase sikap ilmiah mahasiswa dalam melaksanakan praktikum Biologi umum adalah $78,3 \%$ dengan kategori baik hal ini menunjukkan 
bahwa proses pelaksanaan praktikum Biologi umum dapat menumbuhkan sikap ilmiah pada mahasiswa. Dari masing-masing indikator diperoleh, nilai rata-rata sikap ilmiah mahasiswa yang tertinggi adalah pada indikator tanggung jawab dengan rata-rat persentase $87,1 \%$ dan nilai rata-rata sikap ilmiah terendah pada indikator percaya diri dengan persentase $65,5 \%$.

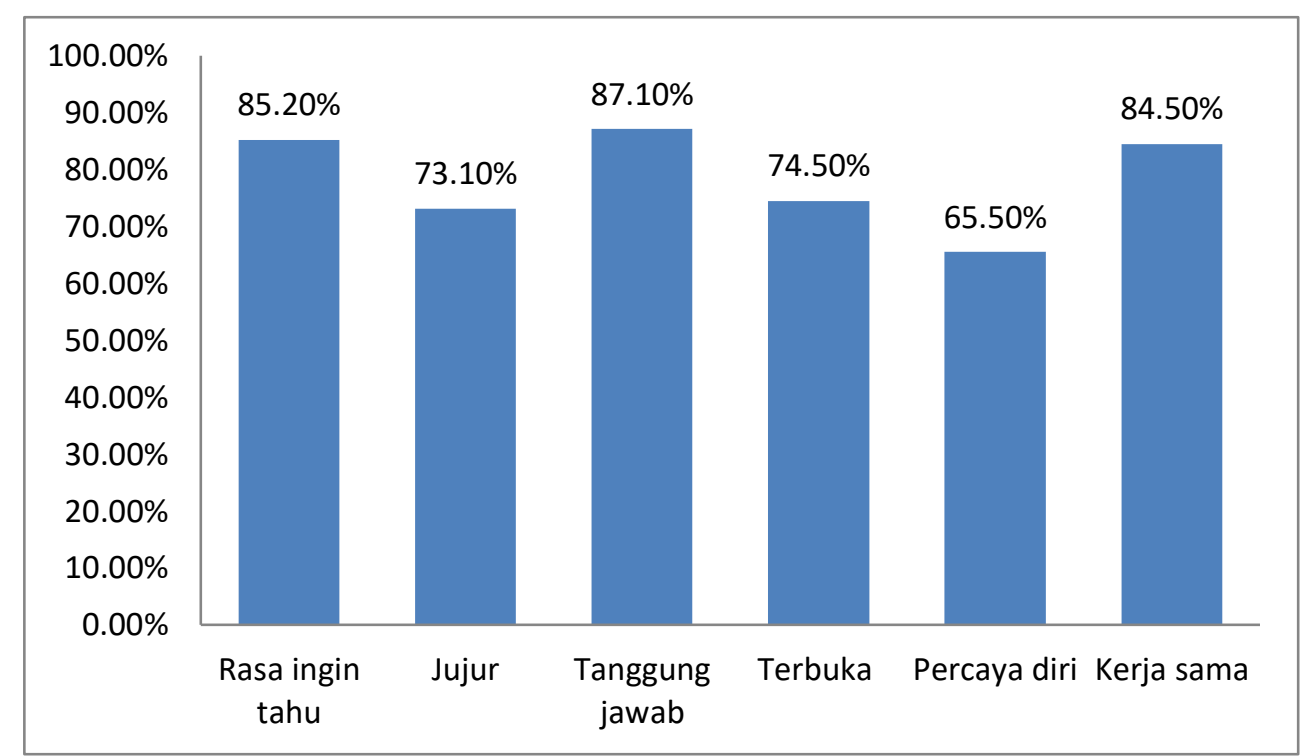

Gambar 1. Bagan Sikap ilmiah mahasiswa pada praktikum Biologi umum

Berdasarkan Gambar 1 dapat diketahui Indikator rasa ingin tahu sikap ilmiah mahasiswa mendapat rata-rata persentase sebesar $85,2 \%$ dengan kategori sangat baik, mahasiswa terlihat antusias dalam memberikan pertanyaan kepada sesama praktikan pada saat persentasi praktikum, dan sebagian dari mahasiswa banyak yang bertanya seputar materi dan cara kerja praktikum Biologi umum kapada asisten praktikum. Rasa keingintahuan mahasiswa yang tinggi dalam praktikum dapat diketahui dari usaha yang dilakukan mahasiswa untuk memahami suatu konsep baru dalam praktikum. Sejalan dengan pendapat Yunita (2012), tingkat sikap ilmiah peserta didik dapat dilihat dari bagaimana mereka memiliki rasa keingintahuan yang sangat tinggi untuk memahami suatu konsep baru dengan kemampuannya tanpa ada kesulitan, kritis terhadap suatu permasalahan yang perlu dibuktikan kebenarannya, dan mengevaluasi kinerjanya sendiri. Sikap rasa ingin tahu menurut Kartono (2012) merupakan sikap dan tindakan yang selalu berupaya untuk mengetahui lebih mendalam dan meluas dari sesuatu yang dipelajarinya, dilihat dan didengar.

Indikator kejujuran memperoleh rata-rata persentase $73,1 \%$ dengan kategori baik. salah satunya dari saat mereka mengerjakan kuis sebelum melaksanakan praktikum, beberapa mahasiswa ada yang mencotek atau bertanya seputar jawaban kepada sesama praktikan namun pada umumnya mengerjakan kuis dengan sendirinya. Pada saat pengamatan praktikum ada sebagian kelompok yang menyalin gambar atau hasil yang didapatkan oleh kelompok lain.

Indikator tanggung jawab dengan rata-rata persentase sebesar 87,1\% dengan kategori sangat baik. Mahasiswa untuk selalu bertanggung jawab terhadap setiap kegiatan praktikum mulai dari peminjaman alat dan bahan oleh kelompok piket, membagi alat dan bahan, membawa objek praktikum sesua arahan asissten dan membersikan labor pada saat selesai praktikum. sehingga pembelajaran dapat berlangsung dengan baik dan lancar, untuk itu sikap bertanggung jawab haruslah dimiliki dan 
ditanamkan dalam diri setiap mahasiswa. Sikap tanggung jawab sangat penting dimiliki oleh mahasiswa, hal ini sejalan dengan pendappat Sardinah, dkk., (2012) beberapa aspek sikap ilmiah dapat dikembangkan dan ditanamkan dalam diri peserta didik salah satunya adalah sikap bertanggung jawab. Menurut Mudalara (2012), selama proses pembelajaran mahasiswa dituntut untuk dapat bertanggung jawab penuh terhadap proses belajarnya sehingga peran dosen didalam pembelajaran lebih sebagai pemberi bimbingan dan arahan jika diperlukan mahasiswa.

Indikator terbuka memperoleh rata-rata persentase $74,5 \%$ dengan kategori baik, pada saat diskusi kelompok belum sepenuhnya dinamis. Beberapa kelompok hanya mengiyakan atau mengikuti apa yang sedang didiskusikan. Dalam hal menerima kritikan/ saran dari teman sekelompoknya, ada bebrapa yang tidak merespon dengan baik atau lapang dada karena ada yang beranggapan hasil yang didapakan pada saat pengamatan itu yang paling benar

Indikator percaya diri dengan rata-rata memperoleh persentase $65,5 \%$ dengan kategori cukup. Banyak dari praktikan yang enggan mengajukan pendapat tentang konsep atau langkah-langkah seputar praktikum, sebagian dari praktikan merasa malu dan takut salah jika mengajukan pendapat atau menjawab pertanyaan dari asisten praktikum.

Indikator kerja sama dengan nilai rata-rata persentase sebesar $84,5 \%$ dengan kategori sangat baik, hal ini dapat dilihat pada saat proses praktikum, hampir semua kelompok ikut serta dalam pengamatan praktikum, dan berperan aktif selama proses praktikum berlangsung. Setiap kelompok melaksanakan praktikum dengan langkah-langkah yang sesuai dengan proses ilmiah. Menurut Vygostky dalam Rustaman (2005), peserta didik dapat bekerja sama secara berkelompok selama pembelajaran, melaksanakan langkah-langkah proses ilmiah.

Sikap ilmiah terbentuk pada saat melakukan proses pembelajaran, aspek sikap ilmiah terdiri dari sikap ingin tahu, sikap kritis, sikap objektif, sikap kerja sama atau menghargai karya orang lain, dan sikap teliti (Yuliani dkk., 2012). Selama proses praktikum, dosen atau asisten dosen sebaiknya melatih dan menumbuhkan sikap ilmiah mahasiswa seperti rasa ingin tahu, kerja sama,percaya diri, tanggung jawab, kerja sama dan terbuka. Pembelajaran berbasis praktikum dapat mengembangkan sikap ilmiah mahasiswa karena pembelajaran menuntut mahasiswa terlibat langsung di dalam kegiatan ilmiah (Sukaesih, 2011).

Menurut Wahyudi (2011), sikap ilmiah memiliki pengaruh yang signifikan dalam meningkatkan prestasi belajar mahasiswa. Secara teoritis, mahasiswa yang memiliki sikap ilmiah yang tinggi akan memiliki ketelitian yang tinggi, rasa ingin tahu yang besar, kejujuran yang tinggi dan tekun dalam belajar. Sehingga mahasiswa yang memiliki sikap ilmiah yang tinggi justru akan memiliki prestasi belajar yang tinggi pula.

\section{SIMPULAN}

Nilai sikap ilmiah pada aspek rasa ingin tahu adalah $85,2 \%$ dengan kategori sangat baik, sikap jujur $73,1 \%$ dengan kategori baik, tanggung jawab $87,1 \%$ dengan kategori sangat baik, terbuka $74,5 \%$ dengan kategori baik, percaya diri 65,5\% dengan kategori cukup dan kerja sama 84,5\% dengan kategori sangat baik. Secara keseluhan sikap ilmiah mahasiswa dalam kegiatan pelaksaan praktikum pada mata kuliah Biologi umum adalah $78,3 \%$ dengan kategori baik. 


\section{RUJUKAN}

Anagun, S.S., and Yasar, S. 2009. Reliability and validity studies of the science and technology course scientific attitude scale. Journal of Turkish Science Education, 6 (2): 43-45.

Dwiyanti, G. 1999. Pengembangan Model Pelaksanaan Praktikum Kimia Organik Skala Mikro di LPTK. Laporan Penelitian. Bandung: FPMIPA IKIP Bandung.

Fakhruddin, Eprina, E., Syahril. 2010. Sikap Ilmiah Siswa dalam Pembelajaran Fisika dengan Penggunaan Media Komputer melalui Model Kooperatif Tipe STAD pada Siswa Kelas X SMA Negeri I Bangkinang Barat. Jurnal Geliga Sains, 4(1): 18-22.

Kartono. 2012. Pengembangan Model Penilaian Sikap IImiah IPA bagi Mahasiswa PGSD. Jurnal FKIP UNS

Martin, J. 1997. Working With Functional Grammar. London: Arnold.

Pujiatuti, Pratiwi. 2013. Pembelajaran IPA Bemakna Bagi Siswa. PGSD FIP , pp. 1-15.

Rustaman, N. 2005. Strategi Belajar Mengajar Biologi. Malang:Universitas Negeri Malang.

Sudijono, A. 2001. Pengantar Evaluasi Pendidikan. Jakarta. PT. Raja Grafindo Persada Sulianto,J.

Sukaesih. 2011. Analisis Sikap IImiah dan Tanggapan Mahasiswa Terhadap Penerapan Model Pembelajaran Berbasis Praktikum. Jurnal Penelitian Pendidikan. 28(1), 77-85

Wahyudi. 2011. Pembelajaran Fisika menggunakan Pendekatan Keterampilan Proses dengan Metode Inkuiri dan Eksperimen ditinjau dari Sikap IImiah dan Kemampuan Menggunakan Alat Ukur Listrik. Tesis PPS UNS

Yuliani, H. Sunarno, W, Suparmi. 2012. Pembelajaran Fisika dengan Pendekatan Keterampilan Proses dengan Metode Eksperimen dan Demonstrasi ditinjau dari Sikap IImiah dan Kemampuan Analisis. Jurnal Inkuiri. 1 (3): 207-216

Yunita, F. 2012. Hubungan Antara Sikap IImiah Siswa Dengan Hasil Belajar Fisika Di Kelas XI IPA MA Negeri Kampar. Program Studi Pendidikan Fisika Fakultas Keguruan dan IImu Pendidikan. Pekanbaru: Universitas Riau. 